\title{
Zeolite-catalyzed biomass conversion to fuels and chemicals
}

Taarning, Esben; Osmundsen, Christian Mårup; Yang, Xiaobo; Voss, Bodil; Andersen, Simon I.; Christensen, Claus $\mathrm{H}$.

Published in:

Energy \& Environmental Science

Link to article, DOI:

$10.1039 / \mathrm{c} 004518 \mathrm{~g}$

Publication date:

2011

Document Version

Publisher's PDF, also known as Version of record

Link back to DTU Orbit

Citation (APA):

Taarning, E., Osmundsen, C. M., Yang, X., Voss, B., Andersen, S. I., \& Christensen, C. H. (2011). Zeolitecatalyzed biomass conversion to fuels and chemicals. Energy \& Environmental Science, 4(3), 793-804. https://doi.org/10.1039/c004518g

\section{General rights}

Copyright and moral rights for the publications made accessible in the public portal are retained by the authors and/or other copyright owners and it is a condition of accessing publications that users recognise and abide by the legal requirements associated with these rights.

- Users may download and print one copy of any publication from the public portal for the purpose of private study or research.

- You may not further distribute the material or use it for any profit-making activity or commercial gain

- You may freely distribute the URL identifying the publication in the public portal

If you believe that this document breaches copyright please contact us providing details, and we will remove access to the work immediately and investigate your claim. 


\title{
Zeolite-catalyzed biomass conversion to fuels and chemicals
}

\author{
Esben Taarning, ${ }^{* a}$ Christian M. Osmundsen, ${ }^{a b}$ Xiaobo Yang, ${ }^{a}$ Bodil Voss, ${ }^{a}$ Simon I. Andersen ${ }^{a}$ \\ and Claus H. Christensen ${ }^{a}$
}

\author{
Received 22nd March 2010, Accepted 1st October 2010 \\ DOI: $10.1039 / \mathrm{c004518g}$
}

Heterogeneous catalysts have been a central element in the efficient conversion of fossil resources to fuels and chemicals, but their role in biomass utilization is more ambiguous. Zeolites constitute a promising class of heterogeneous catalysts and developments in recent years have demonstrated their potential to find broad use in the conversion of biomass. In this perspective we review and discuss the developments that have taken place in the field of biomass conversion using zeolites. Emphasis is put on the conversion of lignocellulosic material to fuels using conventional zeolites as well as conversion of sugars using Lewis acidic zeolites to produce useful chemicals.

\section{Introduction}

Zeolites are crystalline materials composed of $\mathrm{SiO}_{4}$ and $\left[\mathrm{AlO}_{4}\right]^{-}$ tetrahedra. The negative charge of $\left[\mathrm{AlO}_{4}\right]^{-}$tetrahedra is compensated by a cation, maintaining the overall electroneutrality of the zeolite. Charge compensation with $\mathrm{H}^{+}$renders the zeolite highly acidic, which is useful for many catalytic applications. An important feature of zeolites is their microporosity. Many zeolites contain a multidimensional microporous system which has similar dimensions as small molecules. This microporous system allows small reactant molecules to diffuse into the zeolite crystal, thereby allowing access to internal acid sites. The microporous system also adds another important feature to the zeolites, namely shape-selectivity. The sizerestraints of the micropore channels can in some cases restrict the formation of large and often unwanted products. This is the case for the isomerisation of xylene mixtures, where $o$ - and $p$-xylene are formed predominantly over the more bulky and unwanted $m$-xylene isomer. ${ }^{1}$ Alkylation of benzene with ethylene is another important industrial example. ${ }^{2}$ However, most importantly, zeolites are some of the most widely used heterogeneous catalysts for the valorization of hydrocarbon streams in refineries and petrochemical facilities. ${ }^{3,4}$ The most important example is the use of zeolite catalysts in fluid catalytic cracking (FCC), which supplies about $45 \%$ of the global gasoline pool by the cracking of

${ }^{a}$ Haldor Topsøe A/S, Nymollevej 55, 2800 Kgs, Lyngby, Denmark. E-mail: esta@topsoe.dk

${ }^{b}$ Department of Physics, Technical University of Denmark, Anker Engelundsvej 1, 2800 Kgs, Lyngby, Denmark larger hydrocarbon into the gasoline range. ${ }^{5}$ Zeolites also find use as catalysts for the conversion of oxygen containing compounds, and there are many examples of zeolite catalyzed acylations, esterifications and dehydrations. ${ }^{5}$ Of particular importance is the zeolite catalyzed conversion of oxygenates to hydrocarbons. Most known is the conversion of methanol to gasoline (MTG) but many other oxygenates, including ethanol and pyrolysis oil, can also be converted into hydrocarbons that can be used as gasoline.

Biomass has in the past decade become an increasingly important resource for the production of transportation fuels and chemicals. ${ }^{6}$ This utilization is primarily based on biochemical transformations, such as fermentation to produce ethanol from sugars. Biomass conversion based on zeolite catalysis is an alternative approach which could find broad application, especially for the conversion of lignocellulose to transportation fuels and sugars to chemicals. This perspective describes recent developments in this area.

\section{Lignocellulose}

Lignocellulosic biomass is the most abundant bio-resource available and consists of three major components: cellulose, hemicellulose and lignin (Table 1). Cellulose is a linear crystalline polymer composed of glucose units. Due to its high crystallinity, cellulose is very difficult to hydrolyse to glucose. Hemicellulose is different from cellulose since it is a branched amorphous polymer that is made of different pentose and hexose units. Due to the branching and its amorphous nature hemicellulose is easier to hydrolyse into monosaccharides than cellulose. Lignin is the largest

\section{Broader context}

We review the use of zeolites for the conversion of biomass to fuels and chemicals. Zeolites are crystalline microporous aluminosilicate materials that are useful in many applications ranging from use as detergents, ion exchange applications, adsorbents and catalysis. Zeolite catalysis has in particular found use in the upgrade of petroleum to high-quality fuels. However, since biomass is a very different feedstock from petroleum, new approaches are needed if zeolites are to play the same role in the conversion of biomass. In recent years, biomass conversion has attracted tremendous focus and zeolites could play a role in a thermochemical biomass conversion scenario. Selective transformation of sugars to lactic acid derivatives is another area where zeolites can be envisioned to become important catalysts in a future bio-based society. 
Table 1 Composition of different lignocellulosic feedstocks ${ }^{7}$

\begin{tabular}{llll}
\hline $\begin{array}{l}\text { Lignocellulosic } \\
\text { material }\end{array}$ & Cellulose (\%) & Hemicellulose (\%) & Lignin (\%) \\
\hline Corn cobs & 45 & 35 & 15 \\
Wheat straw & 30 & 50 & 15 \\
Rice straw & 32 & 24 & 18 \\
$\begin{array}{ll}\text { Fresh bagasse } \\
\text { Switchgrass }\end{array}$ & 33 & 30 & 19 \\
\hline
\end{tabular}

non-carbohydrate component of lignocellulosic biomass. It is an amorphous polymer of aromatic allylic alcohols that is very resilient towards hydrolysis and cannot be utilized by fermentation.
Many strategies exist for the conversion of lignocellulose to fuels. Second generation bioethanol can be produced by pretreating lignocellulose to open it up for a subsequent enzymatic hydrolysis. This facilitates the release of monosaccharides which can be fermented into ethanol. This process enables non-edible lignocellulose to be used as a source for ethanol, although lignin remains unutilized. Gasification of lignocellulose is a different strategy which enables all the carbon containing species present in the lignocellulose to be utilized, including lignin. The lignocellulose is heated to temperatures in the range of $800-1000{ }^{\circ} \mathrm{C}$ in the presence of a small amount of oxygen. This facilitates the complete break-down into $\mathrm{CO} / \mathrm{CO}_{2}, \mathrm{H}_{2}$ and $\mathrm{H}_{2} \mathrm{O}$. The syngas thus produced can be converted into Fisher-Tropsch diesel or to

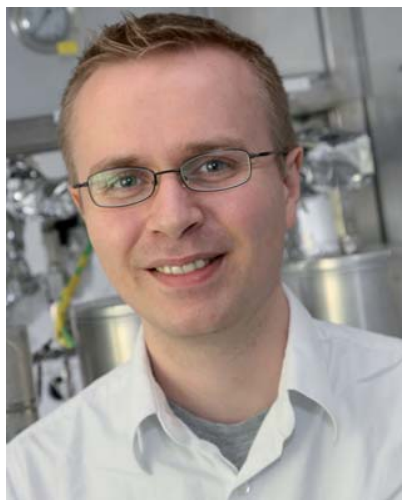

Esben Taarning
Esben Taarning is a research chemist at Haldor Topsøe A/S, working on the conversion of biomass to fuels and chemicals using heterogeneous catalysis. He received an MSc degree in chemistry from the University of Copenhagen in 2005 and in 2009 the PhD degree from the Technical University of Denmark after which he has worked for Haldor Topsøe A/S. The topic of his PhD thesis is the development of green and sustainable chemical reactions.

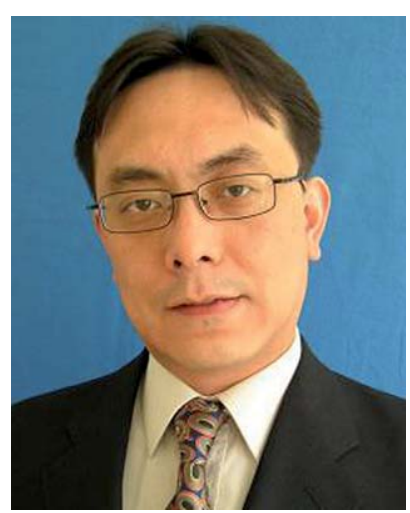

Xiaobo Yang
Dr Xiaobo Yang, holding BSc and MSc degrees of Fudan University, Shanghai, China, obtained his PhD in Chemical Technology in 1999 from University of Kaiserslautern, Germany, under the supervision of Prof. Stefan Ernst with a thesis on the host/guest chemistry of zeolites. Then he held a number of research positions at academic and industrial institutions, working on zeolite synthesis and characterization, among them at ENSCMu with Prof. Henri Kessler, and at University of Pennsylvania with Dr David Olson. Since 2008 Dr Yang has been working at Haldor Topsoe A/S as a Research Chemist on catalytic conversion of biomass to chemicals.

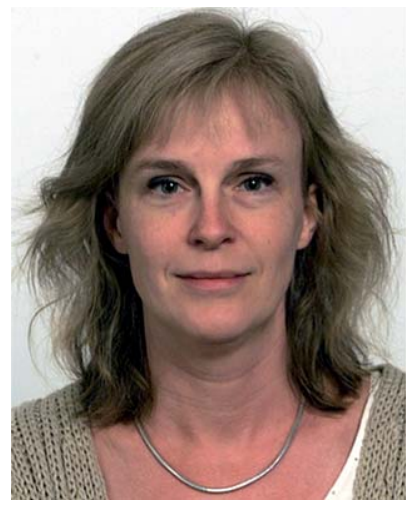

Bodil Voss (b. Feb. 14 ${ }^{\text {th }}$ 1967) is Christian Osmundsen received an MSc in chemical engineering from the Technical University of Denmark (DTU). He is currently a PhD student at the department of physics at DTU under the Catalysis for Sustainable Energy (CASE) Initiative. The focus of the project is the development of methods for converting biomass, in particular carbohydrates, into chemicals and fuels by catalytic means. The work is performed in collaboration with Haldor Topsøe $A / S$. finishing an industrial PhD project in April 2011 on the conversion of biomass to chemicals by heterogeneous catalysis at Haldor Topsøe A/S (Denmark), a world leading supplier of catalysts and technological designs within the fields of bulk chemicals production and environmental processes and in collaboration with the Technical University of Denmark (DTU). Bodil Voss graduated as a Bachelor of Chemical Engineering from DTU in 1990 (Ingeniørakademiet). She was employed at Haldor Topsøe A/S immediately after obtaining her degree and has been working there for 20 years. 
methanol which can be used to produce gasoline using the MTG process. ${ }^{8}$

\section{Pyrolysis oil from lignocellulose}

Pyrolysis of biomass is yet another strategy for the utilization of lignocellulose. By heating lignocellulose in the absence of oxygen, it can be converted into gaseous, liquid and solid materials. The relative distribution of each depends on process parameters such as residence time, temperature and heating rate. In general, long residence times of 15-30 minutes and low temperatures, around $400{ }^{\circ} \mathrm{C}$, favor the formation of solid charcoal whereas flash pyrolysis with residence times shorter than 1 second and temperatures around $500{ }^{\circ} \mathrm{C}$ favor the formation of the liquid pyrolysis oil., ${ }^{9,10}$ Pyrolysis facilitates the spontaneous occurrence of dehydration reactions, retro-aldol reactions and many radical reactions. In flash pyrolysis, high temperatures ensure efficient depolymerization while short residence time minimizes the effect of secondary reactions which otherwise would lead to further thermal decomposition of the pyrolysis oil, resulting in a reduced liquid yield. Yields of liquid pyrolysis oil in the range of $70-75 \%$ are obtainable using flash pyrolysis.

The most important reason to transform lignocelluloses into pyrolysis oil is that it becomes a liquid, which makes further processing less problematic. Pyrolysis achieves a partial breakdown of the macromolecular components of lignocellulose to smaller components such as sugar monomers and decomposition products of these. The lignin part is also depolymerized to some extent, and aromatics such as guaiacols and phenols are typical components found in pyrolysis oil. However, a large part of the lignin and some of the polysaccharides are converted into char, which is difficult to process further.

The elemental composition of pyrolysis oil generally resembles that of the parent lignocellulosic feedstock. ${ }^{10}$ Pyrolysis oil is a viscous black liquid with a similar appearance as crude oil. However, it is fundamentally different in many regards (Table 2).
Pyrolysis oil can be considered a micro-emulsion of various oxygenates such as carboxylic acids, ketones and aldehydes in water and it is immiscible with hydrocarbons. The presence of carboxylic acids renders the pyrolysis oil acidic, with typical $\mathrm{pH}$ values in the range of 2-2.5. Over time, the aldehydes and ketones undergo aldol condensation reactions under these acidic conditions. This causes the pyrolysis oil to change composition and viscosity over time and its acidic nature makes storage difficult due to corrosion issues. Pyrolysis oil has a slightly higher energy density than its parent lignocellulosic precursor but only an energy density of about $40 \%$ of that of diesel at $25 \%$ water content.

\section{Zeolite upgrading of pyrolysis oil}

Through proper separation techniques a number of useful chemicals can be retrieved from pyrolysis oil. ${ }^{13}$ However, the sheer number of components present complicates this approach. Indeed, more than 400 different components have been identified in the oil, and the use of pyrolysis oil as a fuel substitute seems to be a more reasonable strategy. ${ }^{14,15}$ So far, pyrolysis oil has only been used as fuel in a limited number of applications, such as stationary ones. ${ }^{16,17}$ Pyrolysis oil is not useful as a liquid transportation fuel due to the many undesirable characteristics described unless it is upgraded to a more stable fuel product. One way to upgrade pyrolysis oil is by converting it to gasoline using a zeolite catalyst. This facilitates the conversion of pyrolysis oil to a hydrocarbon fraction which resembles gasoline.

When vapors of pyrolysis oil are passed through a bed of zeolite catalyst at $300-500{ }^{\circ} \mathrm{C}$ they are converted to hydrocarbons along with the formation of $\mathrm{H}_{2} \mathrm{O}, \mathrm{CO}_{x}$ and coke. This process thus resembles the MTG process to a great extent. In general, coke formation is much more pronounced when pyrolysis oil is used as feed compared to methanol, and in the order of $30 \%$ of the carbon in the feed ends up as coke on the zeolite. The primary reason for this is that pyrolysis oil contains less effective

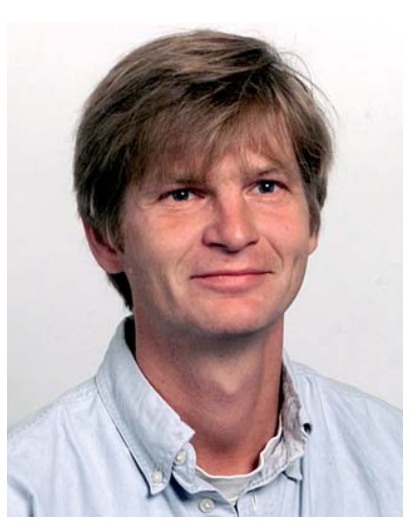

Simon I. Andersen
Simon Ivar Andersen is the Reservoir fluid chemistry discipline manager at Schlumberger DBR Technology Center, Edmonton, Canada. Previously he has been principal research scientist and responsible for a program on renewable chemistry at Haldor Topsoe A/S, Denmark. Before joining Topsoe he was an associate professor in applied thermodynamics Dept. Chem. Eng. Technical University of Denmark. His research interests have been within phase behavior, colloidal chemistry and analysis of complex mixtures such as petroleum as well as catalysis.

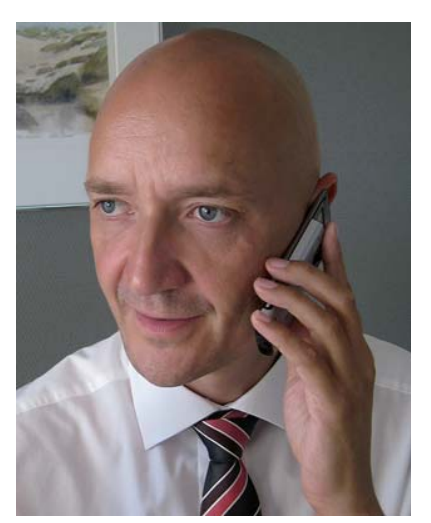

Claus H. Christensen
Claus Hviid Christensen is Chief Executive Officer at LORC (Lindoe Offshore Renewables Center) that is leading the turnaround of the Danish shipyard Lindoe from ship construction to renewable energy technology. Before this, Claus Hviid Christensen was Vice President, $R \& D$ at Haldor Topsøe A/S with responsibility for emerging technology. He came to this position after founding the Danish Center of Excellence for Sustainable and Green Chemistry at the Technical University of Denmark, where he was Professor of Chemistry. Claus Hviid Christensen is also co-founder of Amminex A/S that develops ammonia and hydrogen storage technologies. 
Table 2 Characteristics of pyrolysis oil and diesel fuel $\left(40{ }^{\circ} \mathrm{C}\right.$ and $25 \%$ water $)^{11,12}$

\begin{tabular}{lll}
\hline Physical property & Pyrolysis oil & Diesel fuel \\
\hline Moisture content & $20-30 \mathrm{wt} \%$ & $0.1 \mathrm{wt} \%$ \\
pH & $2.0-2.5$ & - \\
Density & $1.2 \mathrm{~kg} \mathrm{~L}^{-1}$ & $0.94 \mathrm{~kg} \mathrm{~L}^{-1}$ \\
Elementary analysis (wt $\%)$ & & \\
$\mathrm{C}$ & $55-58$ & 85 \\
$\mathrm{H}$ & $5-7$ & 11 \\
$\mathrm{O}$ & $35-40$ & 1 \\
$\mathrm{~N}$ & $0-0.2$ & 0.3 \\
Ash & $0-0.2$ & 0.1 \\
$\mathrm{HHV}$ as produced & $16-19 \mathrm{MJ} \mathrm{kg} \mathrm{kg} \mathrm{k}^{-1}$ & $40 \mathrm{MJ} \mathrm{kg}^{-1}$ \\
Viscosity & $40-100 \mathrm{cp}$ & $180 \mathrm{cp}$ \\
Solids (char) (wt $\%)$ & $0.1-0.5$ & 1.0 \\
Vacuum distillation residue & $\mathrm{Up} \mathrm{to} 50 \mathrm{wt} \%$ & $1 \mathrm{wt} \%$ \\
\hline
\end{tabular}

hydrogen than methanol or ethanol. It is simply a too highly oxidized feed to be converted solely into hydrocarbons, and excess carbon is therefore deposited as coke. The effective hydrogen of a feed can be assessed by the use of Chen's effective $\mathrm{H} / \mathrm{C}$ ratio concept as defined by $(\mathrm{H}-2 \mathrm{O}) / \mathrm{C} .{ }^{18}$ Feeds having high $\mathrm{H} / \mathrm{C}$ ratios in general lead to less coke formation than those having lower ratios. Thus, for methanol the effective $\mathrm{H} / \mathrm{C}$ ratio is 2, while for pyrolysis oil it is below 0.5 .

Oxygen is removed over the zeolites in the form of $\mathrm{H}_{2} \mathrm{O}, \mathrm{CO}$ or $\mathrm{CO}_{2}$. The ideal situation for a highly oxidized feed such as pyrolysis oil is to remove most of oxygen in the form of $\mathrm{CO}_{2}$, as this would effectively enhance the $\mathrm{H} / \mathrm{C}$ ratio and thus lead to reduced coke deposition. However, different organic components tend to lose oxygen in different ways (Table 3). In general, alcohols and phenols lose oxygen in the form of $\mathrm{H}_{2} \mathrm{O}$, whereas aldehydes, formates and carbohydrates primarily lose oxygen as $\mathrm{CO}$ and $\mathrm{H}_{2} \mathrm{O}$. Carboxylic acids lose oxygen as $\mathrm{CO}_{2}$ and $\mathrm{H}_{2} \mathrm{O}$. Acetic acid is therefore a useful component for the formation of hydrocarbons, even though its effective $\mathrm{H} / \mathrm{C}$ ratio is 0 .

Bakhshi and co-workers have tested different catalysts such as H-ZSM-5, H-Y, mordenite, silicalite-1, alumina-silica and various $\mathrm{AlPO}_{4}$ molecular sieves, for pyrolysis oil upgrading in a fixed-bed reactor at temperatures in the range of 290 $410{ }^{\circ} \mathrm{C} .{ }^{20,21} \mathrm{H}-\mathrm{ZSM}-5$ was found to be superior to other catalysts, giving a $34 \mathrm{wt} \%$ organic fraction relative to the pyrolysis oil feed. This fraction was found to contain $87 \%$ hydrocarbons, with toluene and xylenes being the dominant species present. In contrast, when using a less acidic silica alumina catalyst, the organic fraction decreased to $25 \mathrm{wt} \%$ relative to the pyrolysis oil feed. In addition, the organic fraction contained fewer hydrocarbons $(54 \%)$ with aromatics only constituting a minor fraction of these relative to aliphatics. This suggests that the less acidic silica alumina catalyst is not as effective a hydrogen transfer catalyst as the H-ZSM-5 and the aliphatics formed are not converted into the thermodynamically favored aromatics. Also, since aromatics have a lower $\mathrm{H} / \mathrm{C}$ ratio than aliphatic hydrocarbons, more hydrogen has to be put into the aliphatics, which reduces the overall formation of hydrocarbons from pyrolysis oil due to its low hydrogen content. Another strategy that has been used is to co-feed pyrolysis oil with a hydrogen-rich compound in order to reduce the amount of coke formed and increase the amount of carbon that ends up as gasoline. In a study, Dao et al. co-fed methanol with furfural, a model compound representing pyrolysis-oil, at a mass ratio of 70/30. ${ }^{22}$ Here the yield of deoxygenated hydrocarbons increased from below $10 \%$ to $\sim 40 \mathrm{wt} \%$, illustrating the beneficial role of increasing the hydrogen content of the feed.

Gayubo et al. have studied model compounds in order to investigate the molecular pathways taking place in the zeolites when processing pyrolysis oil. ${ }^{23-25}$ Using an H-ZSM-5 zeolite as the catalyst, model compounds representing most of the species present in pyrolysis oil were examined. Here it was found that alcohols undergo dehydration at low temperatures $\left(\sim 250^{\circ} \mathrm{C}\right)$ to form olefins which are converted into alkanes and aromatics at higher temperatures. Acetaldehyde forms large amounts of thermal coke prior to contact with the H-ZSM-5 catalyst, illustrating the unstable nature of many aldehyde components. Acetone initially transforms into isobutene and at higher temperatures this is further transformed into heavier olefins and aromatics and alkanes. Acetic acid was found to undergo ketonization to acetone and $\mathrm{CO}_{2}$ and thus follows the reaction pathway of acetone. Phenol is much less reactive than the other substrates and is only partially converted to propene and butenes at temperatures of $400{ }^{\circ} \mathrm{C}$; its conversion does not markedly change with temperature. 2-Methoxyphenol thermally decomposes in the heating zone, leading to the formation of coke, but it is not easily converted over the H-ZSM- 5 even at $450{ }^{\circ} \mathrm{C}$. From the insight gained when using these model compounds, it is speculated by Gayubo et al. that it could be worthwhile to remove aldehydes and phenolics from the pyrolysis oil prior to conversion over the zeolite in order to reduce the amount of coke formed.

Alternatively, from the view point of process design, FCC type riser reactors could be employed where on-site regeneration of coked catalysts is an option. This approach is widely used in the petroleum industry when processing heavy feedstocks and the coke is not completely lost since the heat released by cokeburning is used to supply heat for the process. The use of FCC catalysts, e.g. H-Y zeolite, has been studied by Vasalos et al. ${ }^{26,27}$ In this study, the pyrolysis oil initially underwent a thermal

Table 3 Formation of $\mathrm{H}_{2} \mathrm{O}, \mathrm{CO}$ and $\mathrm{CO}_{2}$ for various organic species over a H-ZSM-5 zeolite ${ }^{19}$

\begin{tabular}{llll}
\hline & \multicolumn{2}{l}{ Oxygen in gas phase (\%) } \\
\cline { 2 - 4 } Feed compound & $\mathrm{H}_{2} \mathrm{O}$ & $\mathrm{CO}$ & $\mathrm{CO}_{2}$ \\
\hline Methanol & 100 & 0 & 0 \\
Dimethyl ether & 100 & 0 & 0 \\
Guaiacol & 96 & 3 & 1 \\
Glycerol & 92 & 7.5 & 0.5 \\
Xylenol & 93 & 6 & 1 \\
Eugenol & 89 & 9 & 2 \\
Anisole & 88 & 12 & Trace \\
2,4-Dimethyl phenol & 87 & 12 & 1 \\
$o$-Cresol & 80 & 17 & 3 \\
Starch & 78 & 20 & 2 \\
Isoeugenol & 77 & 19 & 4 \\
Glucose & 75 & 20 & 5 \\
Dimethoxymethane & 73 & 6 & 21 \\
Xylose & 60 & 35 & 5 \\
Sucrose & 56 & 36 & 8 \\
$n$-Butyl formate & 54 & 46 & 0 \\
Diphenyl ether & 46 & 46 & 8 \\
Furfural & $14-22$ & $75-84$ & $2.5-3.0$ \\
Methyl acetate & 54 & 10 & 36 \\
Acetic acid & 50 & 4 & 46 \\
\hline
\end{tabular}


hydrotreament, resulting in a liquid yield of up to $42 \mathrm{wt} \%$, with up to $85 \mathrm{wt} \%$ oxygen removed while $6.5 \mathrm{wt} \%$ oxygen remained in the hydrotreated product. ${ }^{26}$ The hydrotreated pyrolysis oil can be separated by distillation, with the light distillate having properties compatible with petroleum gasoline or diesel and can be used directly as blend stocks to the corresponding petroleum fractions. The heavy fraction of the hydrotreated pyrolysis oil can be mixed into the petroleum FCC feeds, such as vacuum gas oils. Experimental results show that co-feeding of this hydrotreated pyrolysis oil with vacuum gas oil at $2.5 \mathrm{wt} \%$ can increase the yields of light cycle oil by $1 \mathrm{wt} \%$ with the concurrent formation of $0.5 \mathrm{wt}^{\%} \%$ more coke. ${ }^{27}$

\section{Catalytic fast pyrolysis}

Pyrolysis processes can be carried out in the presence of a catalyst in order to obtain a more desirable hydrocarbon product in place of pyrolysis oil. An obvious benefit of using a catalyst such as a zeolite is that conversion of lignocellulose to gasoline takes place in a single step, thereby simplifying the process by avoiding condensation and re-evaporation of the pyrolysis oil. The principles in catalytic fast pyrolysis are the same as those for noncatalytic fast pyrolysis; lignocellulose is rapidly heated to a temperature between 300 and $700{ }^{\circ} \mathrm{C}$ using a short residence time and then rapidly cooled in order to achieve high liquid yields and prevent the formation of unwanted by-products. The catalyst ensures further cracking of the pyrolysis intermediates and oxygen removal in the form of $\mathrm{H}_{2} \mathrm{O}, \mathrm{CO}$ or $\mathrm{CO}_{2}$ resulting in the formation of hydrocarbons.

Using a forestry residue biomass from beech wood, Lappas et al. carried out experiments to compare fast pyrolysis with catalytic fast pyrolysis using a FCC catalyst, i.e. Re-USY zeolite. ${ }^{27} \mathrm{With}$ the catalyst, pyrolysis oil yields decreased from $c a$. $75 \%$ to $45-50 \%$, while yields of both gas and char almost doubled. However, the oil product obtained in the catalytic process was found to contain 50\% more hydrocarbons and significantly less oxygenates than in the absence of catalyst, thus illustrating that upgrade of the pyrolysis oil occurs simultaneously as the pyrolysis reaction. The oxygen was removed primarily in the form of water in this study, resulting from the zeolites' ability to catalyze dehydration reactions due to its strong acidity. Samolada et al. have introduced a number of measurable factors which can be used as criteria to evaluate the effectiveness of the catalytic fast pyrolysis processes. ${ }^{28}$ These are: loss of organics (LO), stability index (SI) and water generation (WG). The LO criteria relates to carbon efficiency and the other factors define the efficiency of oxygen removal. Different catalysts, such as H-ZSM-5 and Re-USY, mesoporous Al-MCM-41, alumina, and supported $\mathrm{Fe} / \mathrm{Cr}$ catalysts, were tested for catalytic fast pyrolysis using a model biomass mixture. Here it was found that alumina hardly exhibits any catalytic role with respect to improving the fuel property of the liquid product. MCM-41 was found to be comparably inactive, probably due to the poor structural stability and its low acidity. Zeolites, especially H-ZSM-5, are effective oxygen removal catalysts, although at the expense of organics yield; in comparison with e.g. aluminium containing Al-MCM-41, ${ }^{29,30}$ or Al-MCM-41 synthesized from zeolite seeds, ${ }^{31} \mathrm{H}-\mathrm{ZSM}-5$ produces more $\mathrm{H}_{2} \mathrm{O}$, indicating its stronger dehydration tendency due to its stronger acidity.
Catalytic fast pyrolysis of sugars is a topic that has been investigated by Huber and co-workers. Zeolites H-Y, $\beta$, and H-ZSM-5, silicalite-1 and a silica-alumina have been tested for the catalytic fast pyrolysis of glucose at $600{ }^{\circ} \mathrm{C} .{ }^{32,33} \mathrm{H}-\mathrm{ZSM}-5$ gives the highest yields of aromatics and other (partially) deoxygenated organics, along with by-products such as $\mathrm{CO}, \mathrm{CO}_{2}$, $\mathrm{H}_{2} \mathrm{O}$ and coke. The primary product on silica-alumina is coke. The highest achievable aromatic yield over H-ZSM-5 is $c a .30 \%$ based on carbon, while approximately a similar amount of carbon ending up as coke.

Using the same H-ZSM-5 catalyst Huber and co-workers further studied the conversion of xylitol, cellulose and cellobiose. The more reduced xylitol was found to give higher yields of hydrocarbons (48\%) compared to the glucose-based substrates. This is highly interesting, since glucose can be viewed as being xylitol + CO. Thus, if glucose is first decarbonylated to xylitol, higher gasoline yields should be obtainable. The aromatic product was analyzed and found to contain $c a$. 45\% naphthalene, $20 \%$ toluene, others are benzene, alkylbenzene, and up to $5 \%$ indene.

Fast pyrolysis and catalytic fast pyrolysis are currently hot topics of research and development, but no commercial scale technology has been demonstrated yet. Current state of the art gasoline yields are in the order of $50 \%$ of what is theoretically possible. Challenges are two-fold. On the one hand, highly efficient methods have to be developed to deal with the large amounts of coke. An adaptation of the riser reactor technology applied in FCC processes should be a solution under consideration. On the other hand, to realize rapid heating and short residence time on a reasonably large throughput of feedstock requires sophisticated reactor design. Many different ideas are under investigation, such as fluidized beds, rotating cones, microwave heating, etc. Realistic leads will soon emerge.

Conversion of pyrolysis oil to a hydrocarbon fuel that can be used as a transportation fuel is an important field of research. An interesting strategy that has not been discussed here is hydrotreatment of the pyrolysis oil using HDO catalysts to form a more fuel-like product. $^{34,35}$ This is more desirable from a carbon-perspective, since more carbon ends up in the final hydrocarbon product rather than as coke on the catalyst. However, zeolite catalysis could take an important step forward by achieving a better control of how the oxygen is expelled from the pyrolysis oil. If a larger fraction of oxygen is expelled in the form of $\mathrm{CO}$ or $\mathrm{CO}_{2}$, more hydrogen would be accessible for hydrocarbon formation and consequently less carbon would deposit on the zeolite.

\section{Catalytic conversion of sugars to lactates}

The isomerisation of $\mathrm{C}_{3}$-sugars to lactic acid, which is thermodynamically more stable, is catalyzed by aqueous acids at temperatures of $250-300{ }^{\circ} \mathrm{C}$. However, moderate yields are obtained at best. ${ }^{36}$ Lewis acidic catalysts such as $\mathrm{SnCl}_{2}$ have been demonstrated to be highly active and selective catalysts, achieving a methyl lactate yield of $89 \%$ for the conversion of glyceraldehyde in methanol at $90{ }^{\circ} \mathrm{C} .{ }^{37}$ Unfortunately, the use of a homogeneous catalyst is not practical with respect to catalyst recycling and product purification, and a heterogeneous catalyst would therefore be preferable. It has recently been demonstrated that Lewis acidic zeolites such as $\mathrm{Sn}-\beta$ have unique catalytic 


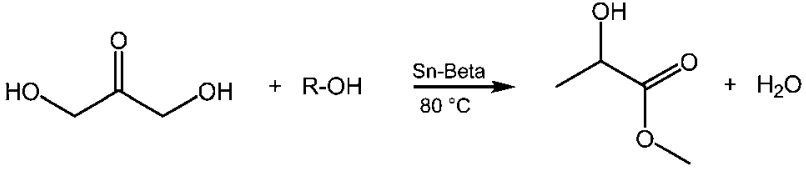

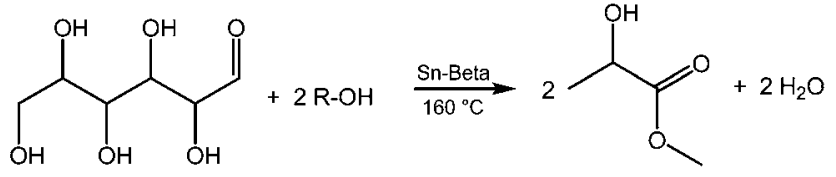

Scheme 1 The conversion of trioses and hexoses to methyl lactate is catalyzed by Lewis acidic zeolites such as Sn-Beta.

activity and are capable of converting $\mathrm{C}_{3}$ - and $\mathrm{C}_{6}$-sugars directly into lactate esters (Scheme 1). ${ }^{36,38}$ The solvent defines which lactate derivative is formed; water leads to the formation of lactic acid whereas methanol leads to methyl lactate.

For $\mathrm{C}_{3}$-sugars, a quantitative yield of methyl lactate can be obtained in methanol at $80{ }^{\circ} \mathrm{C},{ }^{36}$ while yields in the range of 40 $65 \%$ are achieved when using glucose, fructose or sucrose as the substrate at somewhat higher temperatures $\left(160{ }^{\circ} \mathrm{C}\right) .{ }^{38}$ Lower yields are generally obtained when water is used as solvent, which could be resulting from autocatalytic decomposition reactions catalyzed by the formed lactic acid. The reaction pathway from $\mathrm{C}_{3}$-sugars to lactate products is believed to proceed through a preliminary dehydration step, leading to the formation of pyruvaldehyde. Since pyruvaldehyde is highly reactive, it will be present as its hydrate in water and its hemiacetal in methanol. Isomerisation of these species via a 1,2-hydride shift leads to the formation of lactic acid and methyl lactate (Scheme 2, path A).

It has been confirmed that aqueous pyruvaldehyde is also converted into lactic acid using $\mathrm{Sn}-\beta$ as a catalyst, thus supporting the hypothesis that this is a preliminary intermediate. ${ }^{39}$ In this context it was found that aqueous pyruvaldehyde is transformed at lower temperatures than the $\mathrm{C}_{3}$-sugars, suggesting that the dehydration of $\mathrm{C}_{3}$-sugars to pyruvaldehyde is the rate limiting step in the overall reaction. The 1,2-hydride shift resembles the MPVO-redox reaction to a great extent, and $\mathrm{Sn}-\beta$ has previously been demonstrated to be a highly active MPVO-catalyst. ${ }^{40}$ Low levels of tin oxide can be incorporated into the $\beta$ structure during zeolite synthesis, and $\mathrm{Si}-\mathrm{Sn}$ ratio is typically in the order of $90: 1$ to $200: 1$. Since tin is tetravalent, charge compensation is not an issue and $\mathrm{Sn}-\beta$ is therefore not Brønsted acidic. Instead, the discrete tin atoms have Lewis acidic properties and can coordinate to carbonyl and alcohol groups. These functional groups are widely found in natural compounds, and in particular in carbohydrates. A tentative mechanism for 1,2-hydride transfer mediated by a hydrolysed Sn-site is shown in Scheme 3 .

Although Lewis acidic zeolites such as $\mathrm{Sn}-\beta$ and Ti- $\beta$ are superior catalysts for the conversion of $\mathrm{C}_{3}$-sugars to lactate derivatives, conventional aluminium containing $\mathrm{Y}$ and $\beta$ zeolites can also be used. ${ }^{39,41}$ Higher reaction temperatures are generally required for conventional zeolites $\left(110-120^{\circ} \mathrm{C}\right)$ and the product selectivity depends greatly on the nature of the aluminium present in the zeolite. Strongly dealuminated zeolites containing a large degree of extra-framework aluminium have high selectivities towards lactate products. In contrast, zeolites which are Brønsted acidic in nature exhibit low selectivities towards lactates and increased selectivity for the formation of pyruvaldehyde dimethyl acetal. This effect has been illustrated for an Al- $\beta$ zeolite ( $\mathrm{Si}: \mathrm{Al} 65: 1$ ) which yielded 74\% pyruvaldehyde dimethyl acetal and 3\% methyl lactate from dihydroxyacetone in methanol at $115^{\circ} \mathrm{C}$. The same zeolite was tested in a comparable experiment after steam treatment at $750{ }^{\circ} \mathrm{C}$ for 20 hours. Here, the pyruvaldehyde dimethyl acetal yield had dropped to $18 \%$ while $32 \%$ methyl lactate was formed. ${ }^{36}$ This difference in product selectivity is caused by the inability of framework aluminium to catalyze the 1,2-hydride shift of pyruvaldehyde methyl hemiacetal leading to methyl lactate. Instead, further acetalization occurs, and pyruvaldehyde dimethyl acetal becomes the main product (Scheme 2, path B).

$\mathrm{C}_{6}$-Sugars decompose when heated with an aluminium containing zeolite such as Al- $\beta$. However, Lewis acidic zeolites such as $\mathrm{Sn}-\beta$, Ti- $\beta$ and $\mathrm{Zr}-\beta$ are capable of converting $\mathrm{C}_{6}$-sugars into lactic acid derivatives. ${ }^{38}$ Since $\mathrm{C}_{6}$-sugars such as glucose, fructose and sucrose are much more abundant than $\mathrm{C}_{3}$-sugars, this increase in scope is highly important. The overall reaction pathway is believed to involve glucose-fructose isomerisation followed by a retro-aldol reaction of fructose forming the two $\mathrm{C}_{3}$-sugars, glyceraldehyde and dihydroxyacetone (Scheme 4). The retro-aldol reaction is the rate determining step. These $\mathrm{C}_{3}$-sugars are then converted into methyl lactate as described previously. This overall reaction pathway starting from glucose thus resembles the biological glycolysis pathway. Similar yields of methyl lactate are obtained when using either glucose $(43 \%)$ or fructose $(44 \%)$, suggesting that the two are in equilibrium under the reaction conditions. Surprisingly, higher yields of methyl lactate are achieved from sucrose $(65 \%)$ compared to the monosaccharides. The ability of Sn- $\beta$ to catalyze glucose-fructose isomerisation in water was recently reported by Moliner et $a l .{ }^{42}$ When comparing different Lewis acidic materials, Sn- $\beta$ and $\mathrm{Ti}-\beta$ were found to be more active than other tin and

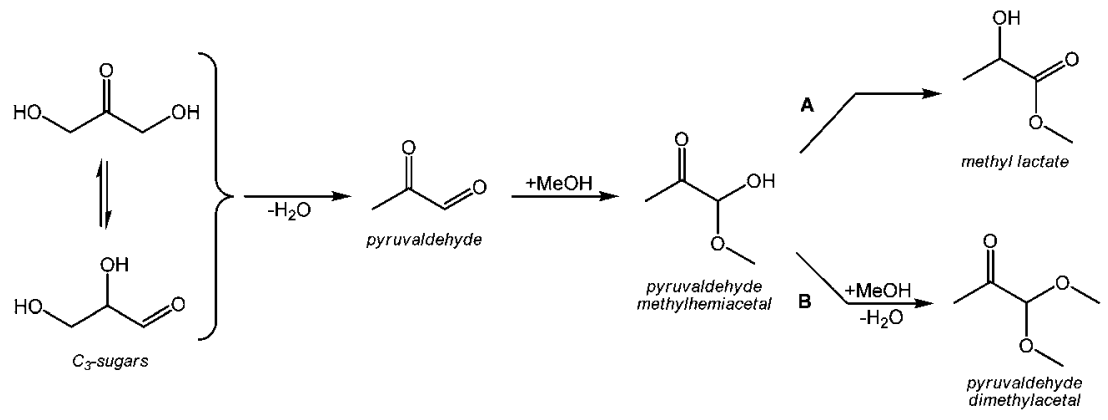

Scheme 2 Proposed reaction pathway for the conversion of trioses to methyl lactate and pyruvaldehyde dimethylacetal. 


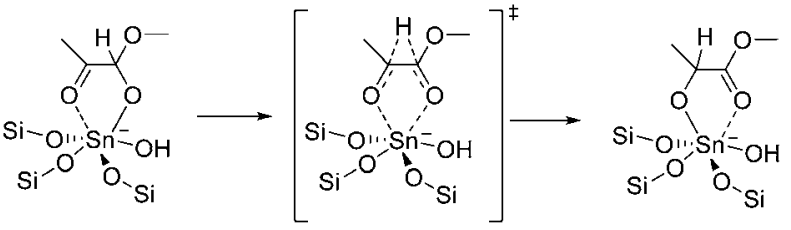

Scheme 3 Tentative transition state mechanism for the 1,2-hydride shift leading to isomerisation of pyruvaldehyde methyl hemiacetal to methyl lactate.

titanium containing materials. This further illustrates how Lewis acidic zeolites might find use as catalysts in carbohydrate conversion.

Currently, little is known about the carbohydrate chemistry catalyzed by Lewis acidic zeolites. However, the ability of the materials to catalyze MPVO-type hydride shifts, retro-aldol reactions and facile dehydration reactions while not having the strong and destructive Brønsted acidic properties of conventional zeolites makes them useful catalysts for converting carbohydrates to different compounds. The Lewis acidic zeolites further have the advantage that they are thermally very stable and can be calcined and reused many times. ${ }^{38}$

These promising characteristics make them real alternatives to fermentation based processes for the production of lactic acid. Currently, lactic acid is produced by fermentation of primarily glucose. ${ }^{44}$ Since it is necessary to maintain a neutral $\mathrm{pH}$ in the fermentation broth, calcium hydroxide is added continuously to precipitate the formed lactic acid. After the fermentation has completed, sulfuric acid is added to reform the acid. The lactic acid is then converted to methyl lactate and purified by distillation. ${ }^{44-46}$ The need for stoichiometric amounts of sulfuric acids and the large amounts of calcium sulfate produced as a byproduct (approx. 1 ton per ton of lactic acid) ${ }^{44}$ make this process less than ideal from an environmental standpoint. In comparison, catalytic production of methyl lactate does not result in the formation of stoichiometric amounts of salt waste and the fact that methyl lactate is formed directly could simplify the purification of it. However, a racemic lactate product is formed when using catalysts, where the fermentative approach yields a stereochemically pure product. This might limit the use of catalytically produced lactates to non-polymer applications.

\section{Dehydration of sugars to furan compounds}

Dehydration of pentoses to yield 2-furancarboxaldehyde, furfural, and hexoses to yield 5-hydroxymethylfurfural, HMF, has been studied for more than a hundred years. Furfural is produced on an industrial scale (approx. $200000 \mathrm{t} \mathrm{a}^{-1}$ ) from agricultural wastes, by hydrolysis followed by dehydration in aqueous acids at high temperatures. ${ }^{43} \mathrm{HMF}$ in contrast is not produced in large scale, although much research has gone into finding viable production methods. HMF can be produced analogously to furfural by dehydration of fructose or hydrolysis/ dehydration of inulin, but the high costs of the substrate compared with comparable chemicals derived from petroleum make large scale production of HMF unattractive, thus HMF is primarily produced for use in the production of a few high value chemicals. ${ }^{43}$ Both furfural and HMF, however, can be converted to a number of interesting chemicals by known processes, and thus have potential for use as platform chemicals. ${ }^{44}$ Scheme 5 shows a number of industrially interesting chemicals that can be produced from HMF. HMF can be oxidized to furan-2,5dicarboxylic acid, FDCA, which can be used as a replacement for terephthalic acid in the production of polymers, ${ }^{45}$ making it interesting as a starting material for the production of biomassderived polymers. Transportation fuels can be produced by hydrogenolysis of $\mathrm{C}-\mathrm{O}$ bonds over a copper-ruthenium catalyst to produce 2,5-dimethylfuran (DMF). This compound is insoluble in water, and has a $40 \%$ higher energy density than ethanol, ${ }^{46}$ making it an interesting alternative for gasoline blending. Alternately liquid alkanes can be produced by condensation reactions between acetone and either HMF or furfural, followed by hydrogenation, over a bi-functional catalyst, such as $\mathrm{Pd} / \mathrm{MgO}-\mathrm{ZrO}_{2}{ }^{47,48}$

The industrial production of HMF is typically performed in a homogeneous system using aqueous sulfuric acid as the catalyst. This approach leads to the formation of a number of byproducts, formed by fragmentation and condensation reactions, ${ }^{45}$ as well as polymeric by-products, known as humins. ${ }^{44}$ The use of a homogeneous catalyst is not optimal, and much research has gone into finding alternative solid catalysts, such as zeolites or acidic resins. Rivalier et al. compared several different zeolites, such as zeolite $\beta, \mathrm{ZSM} 5, \mathrm{Y}$, and mordenite, and found clear differences in conversion and selectivity, with mordenite<smiles>O=CC(O)C(O)C(O)C(O)CO</smiles><smiles>C=CC(O)C(O)C(O)C(=O)CO</smiles>

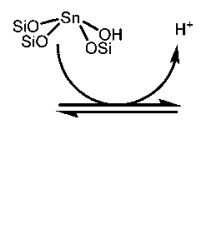

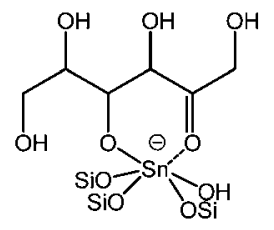

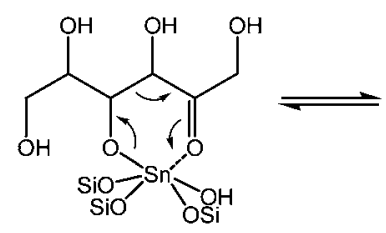

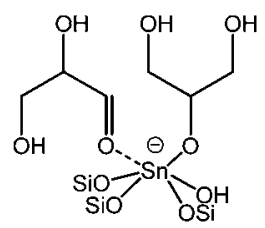

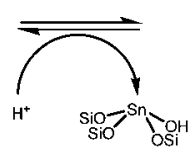<smiles>O=C[C+](O)CO</smiles>

Scheme 4 Proposed reaction pathway for the conversion of glucose to trioses involving isomerisation to fructose, followed by a retro-aldol reaction of fructose leading to dihydroxyacetone and glyceraldehyde. 
giving the best selectivities at more than $90 \%{ }^{49}$ In a study by Moreau et al. the effect of the $\mathrm{Si} / \mathrm{Al}$ ratio on the conversion and selectivity of the process was investigated;50 a maximum yield of $70 \%$ was obtained, when using a zeolite with a Si/Al ratio of 11. In this process HMF was continuously extracted using methyl isobutylketone, MIBK. HMF can rehydrate to give levulinic acid, ${ }^{51}$ and since this reaction is also acid-catalyzed removal of the formed HMF to a neutral phase can be used to avoid further reaction. The partition coefficient in the used system, however, necessitates the use of large volumes of the extraction phase (1:5 water to MIBK) making purification of the product costly. An alternative approach relies on the use of other solvents than water to perform the reaction, coupled with continuous removal of the formed water. In a work by Shimizu et al. water-free DMSO was used as solvent and the reaction was performed at reduced pressure to boil off any water formed during the reaction. ${ }^{52}$ Using zeolite $\mathrm{H}-\beta$, yields of up to $97 \% \mathrm{HMF}$ were achieved, when the reaction was performed in an inert atmosphere, while at standard atmospheric pressure, the yield dropped to $51 \%$. Both aldo- and ketohexoses can be utilized as substrate for HMF production. The reaction pathway from glucose and fructose is given in Scheme 6.

The dehydration can occur both through cyclic intermediates and through acyclic intermediates. Considering only the chemistry of the process, the use of ketohexoses, such as fructose, is generally preferred, as the reaction is both more efficient and selective. ${ }^{51}$ In the dehydration of glucose, the enolization step is very slow, and thus becomes the rate determining step. The use of glucose further complicates the process, in that oligosaccharides with reducing groups can form, which react with intermediates or HMF itself, thereby reducing the overall yield. ${ }^{51}$ However, glucose is much cheaper than fructose, and a change to a process based on glucose, or some polysaccharide of glucose, as substrate would go a long way in making the process more feasible from an industrial standpoint.

\section{Glycerol}

Glycerol is produced on large scale as a by-product in biodiesel production and its production is projected to grow even further as biodiesel production increases. Biodiesel production by

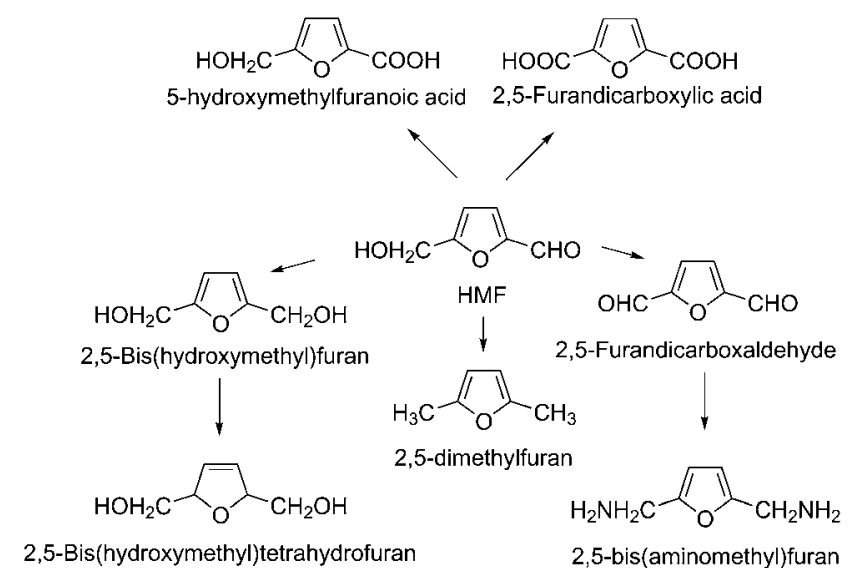

Scheme 5 Overview of industrially interesting chemicals that can be produced from HMF. ${ }^{43,44,46}$ transesterification is accompanied by the co-production of approximately $10 \%$ glycerol. This currently results in the co-production of more than 1 million tons of crude glycerol per year. There is a limited market for high-purity glycerol in the pharmaceutical sector, but this is not able to absorb the large quantities of glycerol produced. In recent years, though, glycerol has found new applications and the chemical companies Solvay and Dow have started using glycerol for the production of epichlorohydrin. Much research has been aimed at converting glycerol into different high-value chemicals. Glycerol transformation using dehydration, hydrogenation, oxidation and etherification as well as acetal and ketal formations have been reported in the literature. Of these, acetalisation and esterification lead to products that can be used as fuel additives, cosmetics, surfactants, plasticizers and pharmaceuticals while the other reactions aim at bulk-type chemical products such as acrolein, 1,3- and 1,2-propandiol. Also acetol, 3-hydroxypropanal, propylene oxide, glyceraldehyde and lactic acid are possible products from glycerol. ${ }^{53-55}$

Acid catalyzed dehydration of glycerol in liquid and gas phase has received much attention. ${ }^{56}$ Acrolein has limited use but it can be transformed into acrylic acid, a very important commodity chemical, by oxidation. Typical catalysts used for the dehydration of glycerol are metal oxides and zeolite catalysts. The boiling point of glycerol is $290^{\circ} \mathrm{C}$ and it is thermally unstable at this high temperature. Catalytic glycerol dehydration reactions, however, often require temperatures in the range of $250-350{ }^{\circ} \mathrm{C}$, so catalyst deactivation due to glycerol by-product formation, coke deposition and acrolein polymerization are all complicating issues. These issues are taken into account by the use of a catalyst that can be regenerated by calcination. The catalyst life-time can be

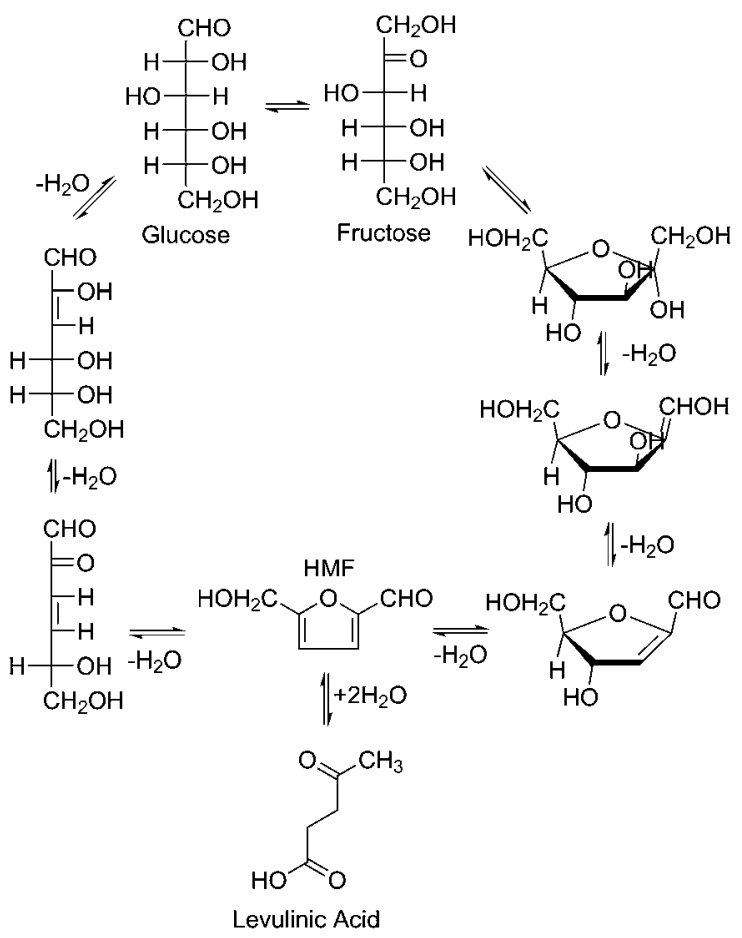

Scheme 6 Pathways for the dehydration of glucose and fructose to HMF. ${ }^{44}$ 
improved by using diluted glycerol rather than pure glycerol. This is particularly true in liquid phase dehydration of glycerol, but dilution with water can often also be used to minimize cokeformation in vapour phase dehydrations. Kartryniok et al. recently gave an excellent review on glycerol dehydration in gas phase showing that zeolites (H-ZSM-5, H-ZSM-11 and H- $\beta$ ) all give $100 \%$ glycerol conversion and acrolein selectivities in the range of $70-83 \%$ at temperatures of $330-360{ }^{\circ} \mathrm{C} .{ }^{56}$ Corma et al. have used a FCC type reactor for glycerol conversion and showed that low temperatures $\left(350{ }^{\circ} \mathrm{C}\right)$ give higher acrolein yields over H-ZSM-5 than using higher temperatures $\left(500^{\circ} \mathrm{C}\right) .^{57}$ However, even at $350{ }^{\circ} \mathrm{C}$ there is a significant build-up of coke. Yoda and Ootawa showed by FT-IR analysis that on H-ZSM-5 the secondary hydroxy group in glycerol interacts preferentially with the $\mathrm{OH}$ of the zeolite, leading to acrolein being formed selectively. ${ }^{58}$ Liquid phase glycerol dehydration is somewhat slower and polymerization of acrolein may hamper the industrial application. The acrolein selectivity found for zeolite catalyzed dehydrations are generally slightly lower than those obtained when using many metal oxides. The lower selectivity is likely caused by the higher acidity of the zeolites compared to metal oxides. When operating in a temperature regime where zeolites are known to form hydrocarbons, coke and hydrocarbon formation is likely to occur simultaneously with the dehydration, thus lowering the acrolein selectivity.

\section{Terpenes}

Terpenes are hydrocarbon compounds found in many places in nature. The basic building block of terpenes is the isoprene unit; terpenes consisting of between 1 and 8 isoprene units are found in the resins secreted from a wide variety of plants, in essential oils, and in pigments, while higher terpenes, polyterpenes, are found in latexes. ${ }^{59}$ Derivates of terpenes are known as terpenoids. Compared to other biomass resources, the available amount of terpenes is relatively low, and the price relatively high, thus most terpenes are used directly, e.g. as fragrances or flavors. Some terpenes, and terpenoids, are, however, produced on a large scale and find use as solvents and as starting materials for the production of fine chemicals. ${ }^{44}$

The isomerisation of citronellal to isopulegol (Scheme 7), an intermediate step in the industrial production of menthol, can be performed using Sn- $\beta$ with almost quantitative yields of pulegols. ${ }^{60}$ Industrially, the production of isopulegol is much more interesting than the other pulegols, thus a high diastereoselectivity is important; using $\mathrm{Sn}-\beta$ it is possible to obtain approximately $85 \%$ isopulegol. The current industrial yield is

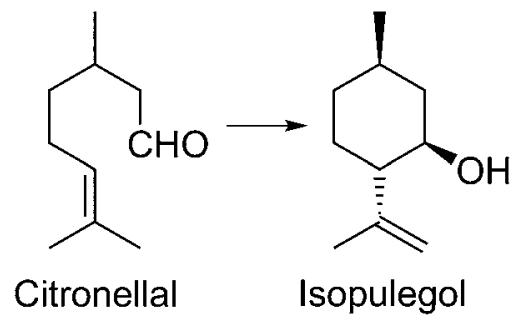

Scheme 7
$92 \%$, however, this is achieved using a homogeneous, watersensitive catalyst.

Another example is the isomerisation of $\alpha$-pinene to camphene (Scheme 8); camphene has a large number of uses, e.g. as an intermediate for the production of fragrance materials, acrylates, terpene-phenol resins, as well as a solvent for varnishes. The industrial production is performed using a $\mathrm{TiO}_{2}$ catalyst, yielding a complex reaction mixture of camphene, limonene, tricyclene, flenchenes and bornylene. ${ }^{44}$ Due to the low reaction rate, a number of other catalysts have been investigated for the reaction, such as zeolites $\beta$, ZSM-5, mordenite, and Y. For zeolite Y, yields of over $40 \%$ camphene, along with $23 \%$ limonene, have been reported, at $85 \%$ conversion. ${ }^{61}$

\section{Dehydration of alcohols}

Ethanol is the largest biochemical produced today and its growth is estimated to continue for many years. Due to the large scale of ethanol production, ethanol can be viewed as a potential feedstock for the production of other compounds, in the same way as naphtha is today. In general, dehydration of ethanol using zeolites leads to the formation of diethyl ether, ethylene or gasoline, depending on the reaction conditions (Fig. 1).

Derouane et al. and others have studied the conversion of methanol and ethanol over H-ZSM-5 zeolite at different temperatures. ${ }^{62-65}$ At low temperatures $\left(150-200{ }^{\circ} \mathrm{C}\right)$, diethyl ether is the dominant species formed, whereas higher temperatures $\left(200-300^{\circ} \mathrm{C}\right)$ lead to the formation of ethylene instead. At temperatures above $250{ }^{\circ} \mathrm{C}$, higher hydrocarbons form and at temperatures above $300{ }^{\circ} \mathrm{C}$ the higher hydrocarbons constitute the majority of the product composition (Fig. 1). At temperatures above $350^{\circ} \mathrm{C}$, the product composition resembles that seen for methanol, where a large fraction of the hydrocarbons is aromatic species. The most notable difference is that ethylated aromatics are formed, rather than the methylated aromatics seen in the MTG reaction.

Diethyl ether is a diesel fuel with excellent cold-start properties and the ability to reduce $\mathrm{NO}_{x}$ emissions in the exhaust gas from diesel engines and has the potential to be an important bio-fuel in the future. ${ }^{66}$ Diethyl ether formation is catalyzed by both Brønsted and Lewis acidic sites and even weakly acidic sites have been demonstrated to be effective catalysts for the formation of diethyl ether. ${ }^{62,65}$

Ethylene is the most important chemical produced, with an annual production exceeding 100 million tons. Currently, ethylene is produced from petroleum and natural gas, either by steam cracking of naphtha or from ethane dehydrogenation. Ethylene can also be obtained from ethanol by dehydration, and commercial scale production of bio-ethylene began in 2009 in

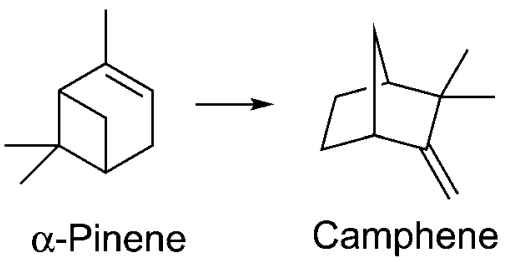

Scheme 8 


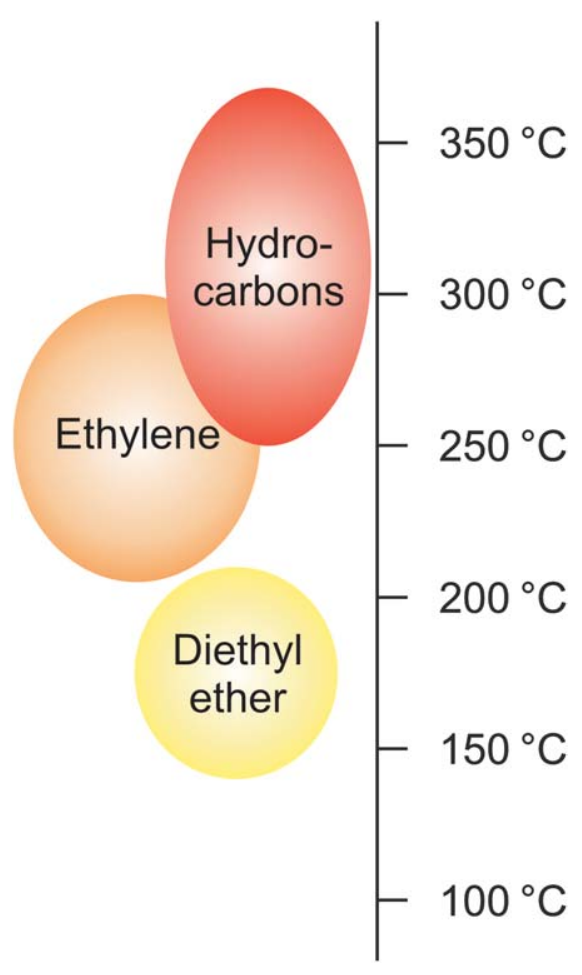

Fig. 1 Product selectivity at various temperatures for the conversion of ethanol over H-ZSM-5.

Brazil. ${ }^{67}$ Ethylene can be obtained in high selectivity over $\mathrm{H}-\mathrm{ZSM} 5$ zeolite catalysts at temperatures in the range of 250 $300{ }^{\circ} \mathrm{C}$. As is the case for many zeolite catalyzed processes, catalyst deactivation due to coke formation eventually occurs and the catalyst has to be calcined in order to regenerate its activity. Hierarchical zeolites, such as nanocrystalline H-ZSM-5, exhibit significantly improved lifetimes compared to conventional H-ZSM-5 for ethylene production at $240{ }^{\circ} \mathrm{C}$. Thus, a lifetime in the order of 500 hours has been reported for nanocrystalline H-ZSM-5, compared to a lifetime of 120 hours for conventional microcrystalline H-ZSM-5. ${ }^{68}$ The presence of water in the feed has been found to moderate the strongly acidic sites and enhance the catalyst activity and selectivity towards ethylene. ${ }^{69}$ Furthermore, water often has a diminishing effect on the rate of coke formation and can thus be an instrument to improve the catalyst lifetime. The use of aqueous rather than anhydrous ethanol will reduce the feed cost. However, ethylene production will likely only be viable in countries such as Brazil, where a large source of cheap ethanol is available. ${ }^{70}$

Conversion of ethanol to gasoline has been studied in continuation of the findings of the MTG process. ${ }^{71}$ The ETG process leads to a hydrocarbon product similar to that obtained in the MTG reaction, consisting primarily of monocyclic aromatics in the $\mathrm{C}_{7}-\mathrm{C}_{10}$ range together with $\mathrm{C}_{5+}$ alkanes, which can be used directly as gasoline. According to the hydrocarbon pool theory the cavities of the zeolites host cyclic organic species from which the gasoline products originate through alkylation and cracking reactions. ${ }^{71}$ Analysis of the organic species present in spent H-ZSM-5 zeolites has been carried out by dissolution of the zeolite crystal in hydrofluoric acid followed by extraction and GC analysis. This analysis shows that they consist of both ethylated and methylated aromatics. This is slightly different from the MTG reaction, in which only methylated aromatics, such as hexamethylbenzene, are present in the micropores. ${ }^{71-73}$ The importance of the zeolite pore architecture has been investigated. ${ }^{69}$ Zeolites having large pores (FAU and BEA) undergo a rapid deactivation of the Brønsted acidic sites, resulting in very low $\mathrm{C}_{3+}$ activity. In comparison, H-ZSM-5 with its smaller pores exhibits a comparable slow deactivation, analogous with what is observed in the MTG process. However, deactivation on H-ZSM-5 is more pronounced for ETG relative to MTG. ${ }^{71}$ The deposited coke consists of polyaromatics and is more condensed on large pore zeolites than on H-ZSM-5. ${ }^{74}$ Using ion exchanged zeolites can also change the lifetime and product selectivity. In a recent study the yield of $\mathrm{C}_{5+}$ products was found to increase when $0.3-0.5 \mathrm{wt}^{\%} \% \mathrm{Fe}$ was exchanged into the H-ZSM-5 zeolite. ${ }^{75}$

Conversion of higher alcohols such as butanol or propanol to gasoline can be achieved using a H-ZSM-5 zeolite. The production of gasoline from these higher alcohols is easier than from methanol or ethanol, since only mildly acidic sites are needed. Even after the strongly acidic sites have deactivated, production of highly branched $\mathrm{C}_{6}-\mathrm{C}_{9}$ olefins from 1-propanol takes place without the formation of aromatics. ${ }^{76}$ These olefins can be hydrogenated into high-octane gasoline. Co-feeding methanol with butanol has also been shown to have a beneficial effect on the production of gasoline from methanol, allowing lower reaction temperatures to be used. ${ }^{77}$ This increased activity for methanol conversion in the presence of butanol could be an effect of butanol being able to maintain the carbon-pool more effectively at lower temperatures than methanol.

\section{Outlook}

The discovery of zeolites has improved the global energy supply tremendously, allowing a higher gasoline production from oil than what was previously possible. Zeolites are today an integral part of any oil refinery and although zeolites initially emerged as catalysts for the conversion of petroleum, they are likely to play an important role in future bio-refineries as well. No matter how bio-refineries will be based, zeolites will have a role to play. Zeolites can be used for the production of gasoline from methanol (gasification), ethanol (fermentation) and oxygenates (pyrolysis), thereby covering the most likely bio-refineries. Zeolites can also be used for the production of olefins, either from methanol, in the MTO process, or by dehydration of ethanol, propanol and butanol. Finally, zeolites could replace, or supplement, biochemical processes in some cases, e.g. for the production of lactates from carbohydrates.

Gasoline production from pyrolysis oil is cost-attractive since this does not require a gasifier or a fermentation and distillation facility, which is the case for the gasification and fermentation based scenarios. However, the serious coking issues described illustrate that this is very difficult to realize. The fundamental problem is that too little hydrogen is available in pyrolysis oil, which results in the deposition of coke on the catalyst, rather than the formation of hydrocarbons. It would be a major breakthrough within zeolite catalysis if the fate of oxygen in the pyrolysis oil could be controlled to a greater extent. If oxygen was expelled primarily as $\mathrm{CO}_{2}$ rather than water, this would result in a higher hydrogen content of the feed and reduce the 
coking significantly. This could improve the productivity of gasoline from pyrolysis oil and improve the catalyst life-time.

Other advances within zeolite catalysis are likely to emerge from new zeotype materials such as stannosilicates $(\mathrm{Sn}-\beta)$ and titanosilicates (TS-1, Ti- $\beta$ ) which have already been demonstrated to be highly active and selective catalysts for the conversion of carbohydrates. These materials have very different catalytic capabilities than conventional aluminosilicate zeolites and seem more compatible with the fragile nature of carbohydrates. These materials have the potential to be broadly applied within biomass conversion in the future.

\section{Acknowledgements}

The Catalysis for Sustainable Energy initiative is funded by the Danish Ministry of Science, Technology and Innovation.

\section{References}

1 A. A. Kaeding, C. Chu, L. B. Young, B. Weinstein and S. A. Butter, J. Catal., 1981, 67, 159-174.

2 G. Bellussi, G. Pazzuconi, C. Perego, G. Girotti and G. Terzoni, J. Catal., 1995, 157, 227-234.

3 A. Corma, Chem. Rev., 1997, 97, 2373-2419.

4 A. Corma, Chem. Rev., 1995, 95, 559-614.

5 Handbook of Heterogeneous Catalysis, ed. G. Ertl, H. Knözinger, F. Schüth and J. Weitkamp, Wiley-VCH, 2nd edn, 2008.

6 C. H. Christensen, J. Rass-Hansen, C. C. Marsden, E. Taarning and K. Egeblad, ChemSusChem, 2008, 1(4), 283-289.

7 R. L. Howard, E. Abotsi, E. L. Jansen van Rensburg and S. Howard, Afr. J. Biotechnol., 2003, 2(12), 602-619.

8 M. Stöcker, Microporous Mesoporous Mater., 1999, 29(1-2), 3-48.

9 A. V. Bridgwater, Appl. Catal., A, 1994, 116, 5-47.

10 A. V. Bridgwater and G. V. C. Peacocke, Renewable Sustainable Energy Rev., 2000, 4, 1-73.

11 A. V. Bridgwater, Chem. Eng. J., 2003, 91, 87-102.

12 D. C. Elliott and G. F. Schiefelbein, Prepr. Pap. - Am. Chem. Soc., Div. Fuel Chem., 1989, 34, 1160.

13 H. Chum, J. Diebold, J. Scahill, D. Johnson, S. Black, H. Schroeder and R. E. Kriebich, ACS Symp. Ser., 1989, 385, 135-151.

14 S. Czernik and A. V. Bridgwater, Energy Fuels, 2004, 18, 590-598.

15 C. Branka, P. Giudicanni and C. D. Blasi, Ind. Eng. Chem. Res., 2009, 42, 3190-3202.

16 M. E. Boucher, A. Chaala and C. Roy, Biomass Bioenergy, 2000, 19, 337-350.

17 M. E. Boucher, A. Chaala, H. Pakdel and C. Roy, Biomass Bioenergy, 2000, 19, 351-361.

18 N. Y. Chen, T. F. Degnan, Jr and L. R. Koenig, CHEMTECH, 1986, 16, 506-511.

19 J. Diebold and J. Scahill, ACS Symp. Ser., 1988, 376, 297-307.

20 R. K. Sharma and N. N. Bakhshi, Energy Fuels, 1993, 7, 306-314.

21 J. D. Adjaye, S. P. R. Katikaneni and N. N. Bakhshi, Fuel Process. Technol., 1996, 48, 115-143.

22 L. H. Dao, M. Haniff, A. Houle and D. Lamothe, ACS Symp. Ser., 1988, 376, 308-316.

23 A. G. Gayubo, A. T. Aguayo, A. Atutxa, R. Prieto and J. Bilbao, Energy Fuels, 2004, 18, 1640-1647.

24 A. G. Gayubo, A. T. Aguayo, A. Atutxa, R. Prieto and J. Bilbao, Ind. Eng. Chem. Res., 2004, 43, 2610-2618.

25 A. G. Gayubo, A. T. Aguayo, A. Atutxa, R. Prieto and J. Bilbao, Ind. Eng. Chem. Res., 2004, 43, 2619-2626.

26 M. C. Samolada, W. Baldauf and I. A. Vasalos, Fuel, 1998, 77, 16671675.

27 A. A. Lappas, S. Bezergianni and I. A. Vasalos, Catal. Today, 2009, $145,55-62$.

28 M. C. Samolada, A. Papafotica and I. A. Vasalos, Energy Fuels, 2000, 14, 1161-1167.

29 E. F. Iliopolou, E. V. Antonakou, S. A. Karakoulia, I. A. Vasalos, A. A. Lappas and K. S. Trian, Chem. Eng. J., 2007, 134, 51-57.
30 E. Antonakou, A. Lappas, M. H. Nielsen, A. Bouzga and M. Stöcker, Fuel, 2006, 85, 2202-2212.

31 K. S. Triantafyllidis, E. F. Iliopoulou, E. V. Antonakou, A. A. Lappas, H. Wang and T. J. Pinnavaia, Microporous Mesoporous Mater., 2007, 99, 132-139.

32 T. R. Carson, T. P. Vispute and G. W. Huber, ChemSusChem, 2008, 1, 397-400.

33 T. R. Carlson, G. A. Tompsett, W. C. Conner and G. W. Huber, Top. Catal., 2009, 52, 241-252.

34 D. C. Elliot, E. G. Baker, J. Piskorz, D. S. Scott and Y. Solantausta, Energy Fuels, 1988, 2, 234-235.

35 D. C. Elliot and A. Oasmaa, Energy Fuels, 1991, 5, 102-109.

36 E. Taarning, S. Shunmugavel, M. S. Holm, J. Xiong, R. M. West and C. H. Christensen, ChemSusChem, 2009, 7, 625-627.

37 Y. Hayashi and Y. Sasaki, Chem. Commun., 2005, 2716-2718.

38 M. S. Holm, S. Saravanamurugan and E. Taarning, Science, 2010, 328, 602-605.

39 R. M. West, M. S. Holm, S. Shunmugavel, J. Xiong, Z. Beversdorf, E. Taarning and C. H. Christensen, J. Catal., 2010, 269, 122-130.

40 A. Corma, M. E. Domine, L. Nemeth and S. Valencia, J. Am. Chem. Soc., 2002, 124, 3194-3195.

41 K. P. F. Jannsen, J. S. Paul, B. F. Sels and P. A. Jacobs, Stud. Surf. Sci. Catal., 2007, 170(B), 1222-1227.

42 M. Moliner, Y. Román-Leshkov and M. E. Davis, Proc. Natl. Acad. Sci. U. S. A., 2010, 107, 6164-6168.

43 F. W. Lichtenthaler, Carbohydrates, in Ullmann's Encyclopedia of Industrial Chemistry, John Wiley \& Sons, Inc., 2003.

44 A. Corma, S. Iborra and A. Velty, Chem. Rev., 2007, 107, 2411-2502.

45 B. Kamm, Angew. Chem., Int. Ed., 2007, 46, 5056-5058.

46 Y. Román-Leshkov, C. J. Barret, Z. Y. Liu and J. A. Dumesic, Nature, 2007, 447, 982-986.

47 C. J. Barret, J. N. Chheda, G. W. Huber and J. A. Dumesic, Appl. Catal., B, 2006, 66, 111-118.

48 G. W. Huber, J. N. Chheda, C. J. Barret and J. A. Dumesic, Science, 2005, 308, 1446-1450.

49 P. Rivalier, J. Duhamet, C. Moreau and R. Durand, Catal. Today, 1995, 24, 165-171.

50 C. Moreau, R. Durand, S. Razigade, J. Duhamet, P. Faugeras, P. Rivalier, P. Ros and G. Avignon, Appl. Catal., A, 1996, 145(14), 211-224.

51 J. Lewkowski, ARKIVOC, 2001, 17-54.

52 K. Shimizu, R. Uozumi and A. Satsuma, Catal. Commun., 2009, 10, $1849-1853$.

53 C.-H. Zhou, J. N. Beltrami, Y.-X. Fan and G. Q. Lu, Chem. Soc. Rev., 2008, 37(3), 527-549.

54 A. Behr, J. Eitling, K. Irawadi, J. Leschinski and F. Lindner, Green Chem., 2008, 10, 13-30.

55 F. Jerôme, Y. Pouilloux and J. Barrault, ChemSusChem, 2008, 1, 586-613.

56 B. Kartryniok, S. Paul, M. Capron and F. Dumeignil, Chem SusChem, 2009, 2, 719-730.

57 A. Corma, G. W. Huber, L. Sauvanaud and P. O'Conner, J. Catal., 2008, 257, 163-171.

58 E. Yoda and A. Ootawa, Appl. Catal., A, 2009, 360, 66-70.

59 M. Eggersdorfer, Terpenes, inUllmann's Encyclopedia of Industrial Chemistry, John Wiley \& Sons, Inc., 2000.

60 A. Corma and M. Renz, Chem. Commun., 2004, 550-551.

61 C. M. López, et al., Catal. Lett., 1999, 62, 221-226.

62 J. Deng, G. Zhang, S. Dong, H. Pan and H. Wang, Appl. Catal., 1988, 41, 13-22.

63 R. Barthos, A. Széchenyi and F. Solymosi, J. Phys. Chem. B, 2006, 110, 21816-21825.

64 E. G. Derouane, J. B. Nagy, P. Dejaifve, J. H. C. van Hoof, B. P. Spekman, J. C. Védrine and C. Naccache, J. Catal., 1978, 53, $40-55$.

65 I. Takahara, M. Saito, M. Inaba and K. Murata, Catal. Lett., 2005, 105, 249-252.

66 K. Kuzuoka and K. Junichi, US Pat., 20080282998, 2008.

67 http://www.rsc.org/chemistryworld/News/2008/March/31030801.asp.

68 J. Bi, X. Guo, M. Liu and X. Wang, Catal. Today, 2010, 149, 143-147.

69 C. B. Phillips and R. Datta, Ind. Eng. Chem. Res., 1997, 36, 44664475 .

70 K. Weissermel and H. J. Arpe, Industrial Organic Chemistry, Wiley, 2003 , p. 63.

71 R. Johansson, S. L. Hruby, J. Rass-Hansen and C. H. Christensen, Catal. Lett., 2009, 127, 1-6. 
72 M. Bjørgen, S. Svelle, F. Joensen, J. Nerlov, S. Kolboe, F. Bonino, L. Palumbo, S. Bordiga and U. Olsbye, J. Catal., 2007, 249, 195-207.

73 M. Bjørgen, F. Joensen, K.-P. Lillerud, U. Olsbye and S. Svelle, Catal. Today, 2009, 142, 90-97.

74 F. F. Madeira, N. S. Gnep, P. Magnoux, S. Maury and N. Cadran, Appl. Catal., A, 2009, 367, 39-46.
75 V. Calsavara, M. L. Baesso and N. R. C. Fernandes-Machado, Fuel, 2008, 87, 1628-1636.

76 U. V. Mentzel, S. Shunmugavel, S. L. Hruby, C. H. Christensen and M. S. Holm, J. Am. Chem. Soc., 2009, 131(46), 17009-17013.

77 F. Joensen, P. E. H. Nielsen, N. C. Schiødt, T. V. W. Janssens and B. Voss, WO 2008071291, 2008. 